\title{
Commentary: Use it or lose it-Cerebral perfusion and aortic arch surgery
}

\author{
Charles M. Wojnarski, MD, MS, and Andrew M. Vekstein, MD
}

\footnotetext{
From the Duke University Medical Center; and the Division of Cardiovascular and Thoracic Surgery, Department of Surgery, Duke University, Durham, NC.

Disclosures: Authors have nothing to disclose with regard to commercial support.

Received for publication March 18, 2019; accepted for publication March 18, 2019; available ahead of print April 30, 2019.

Address for reprints: Charles M. Wojnarski, MD, MS, Duke University Medical Center, 2301 Erwin Rd, Durham, NC 27710 (E-mail: charles.wojnarski@duke.edu).

J Thorac Cardiovasc Surg 2020;159:34-5

$0022-5223 / \$ 36.00$

Copyright (C) 2019 by The American Association for Thoracic Surgery

https://doi.org/10.1016/j.jtcvs.2019.03.078
}

In this issue of the Journal, Hameed and colleagues ${ }^{1}$ present a network meta-analysis of the 3 most common cerebral protection strategies in aortic arch surgery: antegrade cerebral perfusion (ACP), retrograde cerebral perfusion (RCP) and deep hypothermic circulatory arrest alone. The meta-analysis included 68 studies encompassing data from 26,968 patients, and the primary outcomes studied were operative mortality and postoperative stroke. The quality of the statistical analyses performed is excellent, and this work represents the most robust level of evidence published to date on the subject; it is an exhaustive and thoughtful amalgamation of all existing randomized and observational data comparing the 3 perfusion techniques.

With respect to the primary outcomes studied, Hameed and colleagues ${ }^{1}$ found that antegrade and retrograde perfusion strategies had similar, significant reductions in odds of both postoperative stroke (ACP odds ratio [OR], 0.62 95\% confidence interval [95\%CI], 0.51-0.75; RCP OR, 0.66; 95\% CI, 0.54-0.82) and operative mortality (ACP OR, 0.63 ; 95\%CI, 0.51-0.76; RCP OR, 0.57; 95\%CI, 0.45$0.71)$ relative to deep hypothermia alone. They report both traditional random-effect pairwise comparisons and network estimates and generally find concordance between methods. There were no significant differences between techniques with regard to secondary outcomes studied: postoperative transient neurologic deficits, myocardial infarction, respiratory complications, and renal failure.

Network meta-analysis is a relatively new analytic method that allows inclusion of multiple interventions within a single analysis and estimates the relative treatment effect between each pair of treatments compared by means of direct and indirect evidence. ${ }^{2}$ Traditional meta-analytic methods compare only a single pair of interventions by "pooling" estimates with either fixed or random-effects models. By utilizing both direct and indirect estimates, network meta-analysis is able to take into account all available data in calculation of treatment effect estimates. It requires that intervention comparisons be transitive- that no

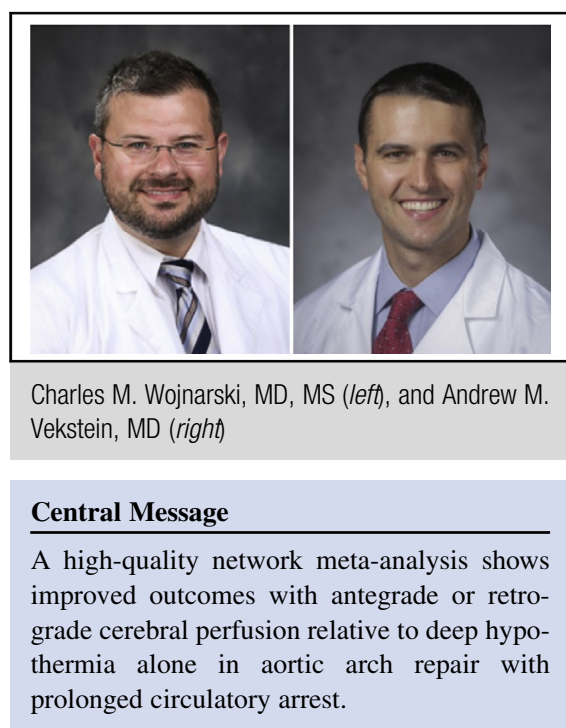

See Article page 18. systematic differences exist other than the treatments being compared - and that there is consistency between effect estimates across various studies. ${ }^{3}$

The clinical reviewers of this article pointed out several areas where clinical variability may have played a part in violating the 2 aforementioned assumptions: arrest temperature, extent of aortic replacement, indication for repair, urgency of operation, and duration of systemic circulatory arrest. As a result, Hameed and colleagues ${ }^{1}$ revised their article and performed additional meta-regression analyses to adjust their effect estimates for these covariates. On doing so, they found no significant inconsistency with regard to all clinical variables when investigating the outcome of operative mortality. With regard to postoperative stroke, longer circulatory arrest times were associated with increased odds of stroke when no cerebral perfusion was used.

As the meta-regression data would suggest, the difference between either antegrade or retrograde cerebral perfusion and deep hypothermia alone only becomes statistically significant after the first quartile of circulatory arrest time ( $>25$ minutes; $P=.01$ for ACP vs deep hypothermic circulatory arrest and $P=.003$ for RCP vs deep hypothermic circulatory arrest; see the Hameed and colleagues ${ }^{1}$ article's Figures E4.1-E4.3). It is important to consider this finding when using this study to guide clinical practice. We would 
expect hemiarch replacements to have circulatory arrest times shorter than 25 minutes. ${ }^{4,5}$ Both antegrade and retrograde cerebral perfusion may be associated with increased overall operative time, complexity, and risk, including increased manipulation of head vessels, which can lead to both atheromatous and air emboli. ${ }^{6,7}$ It is for these reasons that deep hypothermia alone continues to be used at some centers in specific circumstances.

The results of this analysis advise that the best practice for extensive arch surgery with prolonged circulatory arrest times is clear: use either antegrade or retrograde cerebral perfusion, with similar expected outcomes. For less extensive repairs with expected brief periods of circulatory arrest, however, deep hypothermic circulatory arrest remains a reasonable option. Prospective studies to elucidate the optimal cerebral perfusion strategy and degree of hypothermia combination are ongoing. 8,9

\section{References}

1. Hameed I, Rahouma M, Khan FM, Wingo M, Demetres M, Tam DY, et al. Cerebral protection strategies in aortic arch surgery: a network meta-analysis. J Thorac Cardiovasc Surg. 2020;159:18-31.
2. Lumley T. Network meta-analysis for indirect treatment comparisons. Stat Med. 2002;21:2313-24.

3. Salanti G. Indirect and mixed-treatment comparison, network, or multipletreatments meta-analysis: many names, many benefits, many concerns for the next generation evidence synthesis tool. Res Synth Methods. 2012;3: 80-97.

4. Ganapathi AM, Hanna JM, Schechter MA, Englum BR, Castleberry AW Gaca JG, et al. Antegrade versus retrograde cerebral perfusion for hemiarch replacement with deep hypothermic circulatory arrest: does it matter? A propensity-matched analysis. J Thorac Cardiovasc Surg. 2014;148: 2896-902.

5. Gambardella I, Gaudino M, Lau C, Munjal M, Di Franco A, Ohmes LB, et al. Contemporary results of hemiarch replacement. Eur J Cardiothorac Surg. 2017; 52:333-8.

6. Damberg A, Carino D, Charilaou P, Peterss S, Tranquilli M, Ziganshin BA, et al Favorable late survival after aortic surgery under straight deep hypothermic circulatory arrest. J Thorac Cardiovasc Surg. 2017;154:1831-9.e1.

7. Geube M, Sale S, Svensson L. Con: routine use of brain perfusion techniques is no supported in deep hypothermic circulatory arrest. J Cardiothorac Vasc Anesth. 2017;31:1905-9.

8. Leshnower BG, Rangaraju S, Allen JW, Stringer AY, Gleason TG, Chen EP. Deep hypothermia with retrograde cerebral perfusion versus moderate hypothermia with antegrade cerebral perfusion for arch surgery. Ann Thorac Surg. 2019;107: 1104-10.

9. Englum BR, Andersen ND, Husain AM, Mathew JP, Hughes GC. Degree of hypothermia in aortic arch surgery - optimal temperature for cerebral and spinal protection: deep hypothermia remains the gold standard in the absence of randomized data. Ann Cardiothorac Surg. 2013;2:184-93. 